\title{
A new risk assessment method for evaluation of oxidative chemicals using catalase mutant mouse primary hepatocytes
}

\author{
Da-Hong Wang ${ }^{1^{*}}$, Yasuo Ishikawa ${ }^{1}$, Masahiro Miyazaki ${ }^{2}$, Hirofumi Fujita ${ }^{3}$, Ken Tsutsui ${ }^{4}$, \\ Kuniaki Sano ${ }^{5}$, Noriyoshi Masuoka ${ }^{6}$, Keiki Ogino ${ }^{1}$
}

\footnotetext{
${ }^{1}$ Department of Public Health, Okayama University Graduate School of Medicine, Dentistry, and Pharmaceutical Sciences, Okayama, Japan; ${ }^{*}$ Corresponding Author: dahong@md.okayama-u.ac.jp

${ }^{2}$ Department Okayama Gakuin University, Kurashiki, Japan;

${ }^{3}$ Department of Cytology and Histology, Okayama University Graduate School of Medicine, Dentistry, and Pharmaceutical Sciences, Okayama, Japan;

${ }^{4}$ Department of Genome Dynamics, Okayama University Graduate School of Medicine, Dentistry, and Pharmaceutical Sciences, Okayama, Japan;

${ }^{5}$ Department of Neurogenomics, Okayama University Graduate School of Medicine, Dentistry, and Pharmaceutical Sciences, Okayama, Japan;

${ }^{6}$ Department of Life Science, Okayama University of Science, Okayama, Japan.
}

Received 8 March 2011; revised 20 April 2011; accepted 28 April 2011.

\begin{abstract}
We examined the possibility of developing a new risk assessment method for potentially oxidative chemicals by using mouse primary hepatocytes from acatalasemic mice $\left(\mathrm{Cs}^{\mathrm{b}}\right)$ and the wild-type $\left(\mathrm{Cs}^{\mathrm{a}}\right)$ as predictive model. Chemical-induced cytotoxicities, such as hydrogen peroxide and lawsone, a main hair dye ingredient of henna, were examined. We observed the differences in cell survival between the $\mathrm{Cs}^{\mathrm{a}}$ and $\mathrm{Cs}^{\mathrm{b}}$ in a dose-dependant manner after treatment with either hydrogen peroxide or lawsone, supporting the usefulness of this newly established method for hazard identification of oxidative chemicals in a risk assessment process. More chemicals will be tested to confirm the usefulness of this method for the preliminary screening of oxidative chemicals before animal experimentation.
\end{abstract}

Keywords: Catalase-Mutant Mouse Hepatocytes; Reactive Oxygen Species; Hydrogen Peroxide; Hazard Assessment; Lawsone Cytotoxicity

\section{INTRODUCTION}

More and more chemicals are synthesized for industrial and consumer use, it is impossible to finish long-term rodent bioassay for detection of carcinogens and identification of hazards in all chemicals because it involves large numbers of animals and is extremely expensive. Therefore, simple and efficient pre-screening alternatives to animal experimentation are desirable [1]. Nowadays, there has been an increasing awareness that the cellular formation of highly reactive oxygen species (ROS) such as hydrogen peroxide $\left(\mathrm{H}_{2} \mathrm{O}_{2}\right)$ or hydroxyl radicals likely cause the DNA lesions [2]. Catalase and glutathione peroxidase are the most important enzymes capable of removing intracellular $\mathrm{H}_{2} \mathrm{O}_{2}$ in biological systems [3-5], and catalase particularly plays a critical role when $\mathrm{H}_{2} \mathrm{O}_{2}$ is overproduced. Catalase-mutant acatalasemic mouse was established by Feinstein et al. through a large scale screening of the progeny of irradiated $\mathrm{C} 3 \mathrm{H}$ mice [6]. A point mutation at amino acid 11 (from glutamine to histidine) of $\mathrm{Cs}^{\mathrm{b}}$ mouse catalase is responsible for its catalase deficiency $[7,8]$. In the present study, we examined the possibility of developing a new risk assessment method for evaluation of oxidative chemicals using mouse primary hepatocytes from acatalasemic mice $\left(\mathrm{Cs}^{\mathrm{b}}\right)$ and the wild-type $\left(\mathrm{Cs}^{\mathrm{a}}\right)$ as predictive model.

\section{MATERIALS AND METHODS}

\subsection{Chemicals}

Hydrogen peroxide, lawsone (2-hydroxy-1,4-naphthoquinone), kanamycin sulfate, insulin, and dexamethasone sodium phosphate, were purchased from Wako Pure Chemical Industries (Osaka, Japan). Cell counting kit (WST-8) from Dojindo Company (Osaka, 
Japan). All other chemicals were obtained from Sigma Chemical Co (St. Louis, USA) unless otherwise mentioned.

\subsection{Hepatocyte Isolation}

Adult male wild-type $\left(\mathrm{C} 3 \mathrm{H} / \mathrm{AnLCs}^{\mathrm{a}} \mathrm{Cs}^{\mathrm{a}}\right)$ and acatalasemic $\left(\mathrm{C} 3 \mathrm{H} / \mathrm{AnLCs}^{\mathrm{b}} \mathrm{Cs}^{\mathrm{b}}\right)$ mice were used in this study. They were anaesthetized intraperitoneally with $9 \mu \mathrm{l} / \mathrm{g}$ body weight of pentobarbital sodium (10\% in PBS) and then the liver was first perfused at $37^{\circ} \mathrm{C}$ with EGTA at a flow rate of $5.5 \mathrm{ml} /$ minute for 10 minutes and thereafter with collagenase at the same flow rate for 15 minutes as described previously $[9,10]$. The yield of isolated hepatocytes was determined with a hemocytometer, and their viability was evaluated with the standard trypan blue exclusion method. The viability of the isolated hepatocytes was around $90 \%$. The isolated hepatocytes $\left(5 \times 10^{6}\right)$ were seeded into $100-\mathrm{mm}$-diameter plates or 96 -well plates containing serum free hepatocyte growth medium (HGM) $[11,12]$ supplemented with $1 \mu \mathrm{M}$ insulin (Sigma Chemical Co, St. Louis, MO), $1 \mu \mathrm{M}$ dexamethasone sodium phosphate, $0.1 \mathrm{mg} / \mathrm{ml}$ kanamycin sulfate, and allowed to attach for $24 \mathrm{~h}$ before used in the experiments.

\subsection{Confirmation of the Genotype of Catalase Mutant Mouse Hepatocytes}

Genomic DNA was purified from primary cultured hepatocytes of $\mathrm{Cs}^{\mathrm{a}}$ and $\mathrm{Cs}^{\mathrm{b}}$ using Wizard Genomic DNA Purification Kit (Promega Corporation, WI) and was used as a template for PCR amplification of the catalase gene segment encompassing the $\mathrm{Cs}^{\mathrm{b}}$ mutation site. The primers, 5'-CGGGTGGAGACCAGACCGCT-3' and 5'-TGCGAGGCCCGCTGCTCCTT-3', were used to target a $141 \mathrm{bp}$ fragment of the mouse catalase gene [13]. PCR amplification was performed for 35 cycles $(30 \mathrm{~s}$ at $98^{\circ} \mathrm{C}$ for denaturation, $20 \mathrm{~s}$ at $58^{\circ} \mathrm{C}$ for annealing, and 40 $\mathrm{s}$ at $68^{\circ} \mathrm{C}$ for extension) in a final volume of $20 \mu \mathrm{l}$ with $50 \mathrm{ng}$ of genomic DNA, $50 \mathrm{nM}$ primers, and $0.05 \mathrm{U} / \mathrm{ml}$ LA Taq DNA polymerase under the conditions recommended by the manufacturer (TaKaRa Biochemicals, Japan). Amplified products were purified by ethanol precipitation, digested with restriction enzyme NdeI, and subjected to agarose gel electrophoresis (4\% NuSieve GTG agarose). DNA bands were visualized by staining with ethidium bromide.

\subsection{Cell Viability Assay}

Primary hepatocytes seeded into 96-well plates at a density of $1.2 \times 10^{4}$ per well were used to evaluate the cytotoxic effect of chemicals. Various concentrations of test compounds $\left(\mathrm{H}_{2} \mathrm{O}_{2}\right.$ and lawsone were added to the cells and incubated at $37^{\circ} \mathrm{C}$ for $24 \mathrm{~h}$. Cell viability was measured using the WST- 8 assay, based on the reduction of the tetrazolium salt to a water-soluble formazan product by the cellular dehydrogenase [14]. Absorbance was measured at $450 \mathrm{~nm}$ by microplate reader. The survival of cells exposed to chemicals was expressed as a percentage of cell survival in the negative control group based upon the following formula: Survival $(\%)=(\mathrm{Ab}-$ sorbance of sample - Absorbance of blank)/(Absorbance of negative control - Absorbance of blank). At least three tests were performed in each experiment.

\subsection{Statistic Analysis}

Significant differences $(\mathrm{p}<0.05)$ among groups were determined by two-way analyses of variance (two-way ANOVA) by SPSS 15.0 statistical program package (SPSS Inc., Illinois, USA).

\section{RESULTS AND DISCUSSION}

\subsection{The $C s^{\text {b }}$ Catalase Mutant Gene Is Susceptible to Ndel Digestion}

Since a point mutation at amino acid 11 (from glutamine to histidine) of $\mathrm{Cs}^{\mathrm{b}}$ mouse catalase gene is responsible for the deficient catalase activity $[7,8]$, there is a recognition site for $N d e I$ that can cut the targeted $141 \mathrm{bp}$ fragment of $\mathrm{Cs}^{\mathrm{b}}$ band into 2 fragments of 108 and $33 \mathrm{bp}$. Figure 1 showed the genomic PCR products with or without the enzymatic digestion of NdeI. The 141-bp target region in the wild-type mouse $\mathrm{Cs}^{\mathrm{a}}$ catalase gene was not cleaved by the enzyme, however, all the 141-bp products of the $\mathrm{Cs}^{\mathrm{b}}$ catalase mutant gene were cleaved to 2 fragments of 108 and $33 \mathrm{bp}$ (the $33 \mathrm{bp}$ fragment is not visible here) by NdeI. The results agreed with that of previous reported [13].

\subsection{Difference in Cytotoxic Effects Induced by Oxidant $\mathrm{H}_{2} \mathrm{O}_{2}$ on Mouse Primary Hepatocytes}

In Table 1, catalase-mutant mouse $\mathrm{Cs}^{\mathrm{b}}$ hepatocytes showed a significantly higher susceptibility to $\mathrm{H}_{2} \mathrm{O}_{2}$ in comparison with the wild-type $\mathrm{Cs}^{\mathrm{a}}$, and the cytotoxic effects of $\mathrm{H}_{2} \mathrm{O}_{2}$ on both cell groups were dose dependent.

Since a point mutation at amino acid 11 of $\mathrm{Cs}^{\mathrm{b}}$ mouse catalase gene is responsible for catalase deficiency, $\mathrm{H}_{2} \mathrm{O}_{2}$ exposed to $\mathrm{Cs}^{\mathrm{b}}$ hepatocytes could not be fully decomposed, which markedly affected the cell survival compared to that of the wild-type $\mathrm{Cs}^{\mathrm{a}}$. Therefore, based on the cell viability, we can use the $\mathrm{Cs}^{\mathrm{a}}$ and $\mathrm{Cs}^{\mathrm{b}}$ as predictive models to assume whether $\mathrm{H}_{2} \mathrm{O}_{2}$ involves in the chemical-induced cytotoxicity, which would be helpful for the preliminary screening of the potential oxidative chemicals. 


\begin{tabular}{c|c}
$\mathrm{Cs}^{\mathbf{a}}$ & $\mathrm{Cs}^{\mathbf{b}}$ \\
\hline NdeI & \multicolumn{2}{|c}{ NdeI } \\
$(-) \quad(+)$ & $(-) \quad(+)$
\end{tabular}

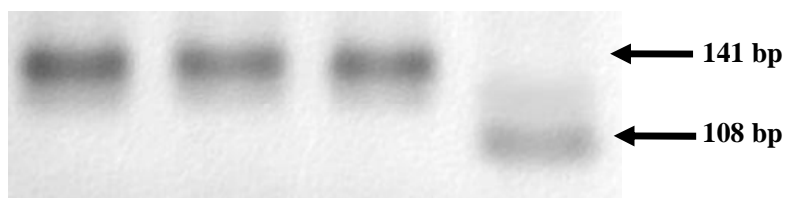

Figure 1. The genomic PCR products with or without the enzymatic digestion of NdeI.

Table 1. Comparison of $\mathrm{H}_{2} \mathrm{O}_{2}$-induced cytotoxic effect on primary hepatocytes ${ }^{\#}$.

\begin{tabular}{ccc}
\hline Treatment $\mathrm{H}_{2} \mathrm{O}_{2} \#$ & $\mathrm{Cs}^{\mathrm{a}}$ & $\mathrm{Cs}^{\mathrm{b}}$ \\
\hline None & 100 & 100 \\
$3.75 \mathrm{mM}$ & $74.2 \pm 2.5$ & $18.3 \pm 0.4$ \\
$7.5 \mathrm{mM}$ & $54.0 \pm 3.8$ & $15.6 \pm 1.6$ \\
$15 \mathrm{mM}$ & $36.0 \pm 4.1$ & $12.8 \pm 1.1$ \\
\hline
\end{tabular}

\#Data are expressed as percentage of mean \pm SD. At least three tests were performed in each experiment. Differences within and among groups were evaluated by two-way ANOVA; ${ }^{\#}$ Concentrations of $\mathrm{H}_{2} \mathrm{O}_{2}$ were expressed as final concentrations in the reaction cultures. $\mathrm{P} 1<0.01$ (comparison between groups of $\mathrm{Cs}^{\mathrm{a}}$ and $\mathrm{Cs}^{\mathrm{b}}$ ). $\mathrm{P} 2<0.001$ (comparison among groups of $\mathrm{H}_{2} \mathrm{O}_{2}$ concentrations).

\subsection{Comparison of Lawsone-Induced Cytotoxicity on Mouse Primary Hepatocytes}

Then, we further tested the cytotoxic effect of lawsone, a main color ingredient of hair dye henna, on mouse primary hepatocytes. Lawsone has been reported causing mutagenicity/genotoxicity both in vitro and in vivo [15] by the Scientific Committee on Cosmetic Products and Non-Food Products (SCCNFP), a scientific advisory body to the European Commission in matters of consumer protection. Figure 2 demonstrated that in comparison with the wild-type $\mathrm{Cs}^{\mathrm{a}}$ hepatocytes, the survival of catalase-mutant mouse $\mathrm{Cs}^{\mathrm{b}}$ hepatocytes was significantly reduced by lawsone treatment, showing $86.1 \%$ in $\mathrm{Cs}^{\mathrm{a}}, 38.0 \%$ in $\mathrm{Cs}^{\mathrm{b}}$ even at $100 \mu \mathrm{M}$ lawsone exposure. Both cell groups dose-dependently detected cytotoxic effects of lawsone.

Catalase is an important component of the cellular defenses against the toxicity induced by $\mathrm{H}_{2} \mathrm{O}_{2}$ and its products [4]. Wang et al. reported that the catalase activity in liver of $\mathrm{Cs}^{\mathrm{b}}$ mice were $39.6 \%$ of that in wild-type $\mathrm{Cs}^{\mathrm{a}}$ [16]. Lawsone was reported to generate $\mathrm{H}_{2} \mathrm{O}_{2}$ in phosphate buffer system [17]. The present study found lawsone treatment markedly reduced cell viabilities in

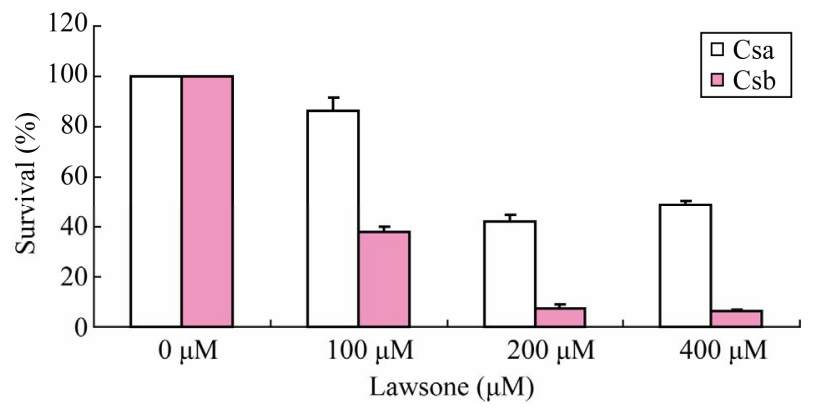

Figure 2. Comparison of lawsone-induced cytotoxic effect on primary hepatocytes. Data are expressed as percentage of mean \pm SD. At least three tests were performed in each experiment. There were significant differences between $\mathrm{Cs}^{\mathrm{a}}$ and $\mathrm{Cs}^{\mathrm{b}}(\mathrm{P}<$ $0.001)$ and among exposure concentrations of lawsone $(\mathrm{P}<$ 0.001 ) evaluated by two-way ANOVA.

catalase-mutant mouse $\mathrm{Cs}^{\mathrm{b}}$ hepatocytes in comparison with in wild-type $\mathrm{Cs}^{\mathrm{a}}$, suggesting that $\mathrm{H}_{2} \mathrm{O}_{2}$ was increasingly produced in the process of lawsone cytotoxicity.

\section{CONCLUSIONS}

The present study has attempted to develop a new assessment method for evaluation of oxidative chemicals using mouse primary hepatocytes from catalase-mutant mouse $\mathrm{Cs}^{\mathrm{b}}$ and the wild-type $\mathrm{Cs}^{\mathrm{a}}$ as predictive model. The differences in cell survival between the $\mathrm{Cs}^{\mathrm{a}}$ and $\mathrm{Cs}^{\mathrm{b}}$ in a dose-dependant manner support the usefulness of this newly established method for hazard identification of oxidative chemicals in a risk assessment process. More chemicals will be tested to confirm the usefulness of this method for the preliminary screening of oxidative chemicals before animal experimentation.

It is known that most primary cell cultures have limited lifespan. The primary cultured hepatocytes employed in our study can be used for 5 - 6 days, during which the hepatocytes are supposed to maintain most of their in vivo functional characteristics in culture $[18,19]$, and they are expected to be possible predictive models for large scale screening of oxidative chemicals if the issue of long-term storage of primary hepatocytes can be solved.

\section{ACKNOWLEDGEMENTS}

This work was supported by Grant-in-Aid for Scientific Research from the Ministry of Education, Science and Culture of Japan (21310022).

\section{REFERENCES}

[1] Andersen, M.E. and Krewski, D. (2009) Toxicity tesing in the 21 st century: Bringing the vision to life. Toxicological Sciences, 107, 324-330. doi: $10.1093 /$ toxsci $/ \mathrm{kfn} 255$ 
[2] Halliwell, B. and Gutteridge, J.M.C. (2007) Cellular responses to oxidative stress: adaptation, damage, repair, senescence and death. In: Halliwell, B., Gutteridge, J.M.C., Eds., Free Radicals in Biology and Medicine, 4th Edition, Oxford University Press, New York, pp.187-267.

[3] Cohen, G. and Hochstein, P. (1963) Glutathione peroxidase: The primary agent for the elimination of hydrogen peroxide in erythrocytes. Biochemistry, 2, 1420-1428. doi:10.1021/bi00906a038

[4] Scott, M.D., Lubin, B.H., Zuo, L., Kuypers, F.A. (1991) Erythrocyte defense against hydrogen peroxide: Preeminent importance of catalase. The Journal of Laboratory and Clinical Medicine, 118, 7-16.

[5] Boveris, A. and Chance, B. (1973) The mitochondrial generation hydrogen peroxide. Biochemical Journal, 134, 707-716.

[6] Feinstein, R.N., Howard, J.B., Braun, J.T. and Seaholm, J.E. (1966) Acatalasemic and hypocatalasemic mouse mutants. Genetics, 53, 923-933.

[7] Shaffer, J.B. and Preston, K.E. (1990) Molecular analysis of an acatalasemic mousemutant. Biochemical and Biophysical Research Communications, 173, 1043-1050. doi:10.1016/S0006-291X(05)80891-5

[8] Wang, D.-H., Tsutsui, K., Sano, K., Masuoka, N. and Kira, S. (2001) cDNA cloning and expression of mutant catalase from the hypocatalasemic mouse: Comparison with the acatalasemic mutant. Biochimica et Biophysica Acta, 1522, 217-220.

[9] Miyazaki, M. (1977) Primary culture of adult rat liver cells. I. Preparation of isolated cells from trypsin-perfused liver of adult rat. Acta Medica Okayama, 31, 351360 .

[10] Kondo, A., Miyazaki, M., Pu, H., Gao, C. and Namba, M. (1999) Establishment and cellular characteristics of a hepatocyte cell line (OUMS-31) derived from an acatalasemic mouse. In Vitro Cellular \& Developmental Biology-Animal, 35, 155-158. doi:10.1007/s11626-999-0018-4

[11] Block, G.D., Locker, J., Bowen, W.C., Petersen, B.E., Katyal, S., Strom, S.C., Riley, T., Howard, T.A. and Michalopoulos, G.K. (1996) Population expansion, clonal growth, and specific differentiation patterns in primary cultures of hepatocytes induced by HGF/SF, EGF and TGF alpha in a chemically defined (HGM) medium. The Journal of Cell Biology, 132, 1133-1149. doi:10.1083/jcb.132.6.1133

[12] Miyazaki, M., Akiyama, I., Sakaguchi, M., Naka Shima, E., Okada, M., Kataoka, K. and Huh, N.H. (2002) Improved conditions to induce hepatocytes from rat bone marrow cells in culture. Biochemical and Biophysical Research Communications, 298, 24-30. doi:10.1016/S0006-291X(02)02340-9

[13] Wang, D.-H., Tsutsui, K. and Kira, S. (2001) Detecting genotypes of catalase mutant mice by genomic polymerase chain reaction and restriction analysis. Analytical Biochemistry, 299, 116-117. doi:10.1006/abio.2001.5356

[14] Tominaga, H., Ishiyama, M., Ohseto, F., Sasamoto, K., Hamamoto, T., Suzuki K. and Watanabe, M. (1999) A water-soluble tetrazolium salt useful for colorimetric cell viability assay. Annals of Communications, 36, 47-50. doi: $10.1039 / \mathrm{a} 809656 \mathrm{~b}$

[15] Scientific Committee on Cosmetic Products and Non-Food Products Intended for Consumers (2004) Opinion concerning lawsone. Colipa No. C146. SCCNFP/0798/04, February 16.

[16] Wang, D.-H., Masuoka, N. and Kira, S. (2003) Animal model for oxidative stress research-catalase mutant mice. Environmental Health and Preventive Medicine, $\mathbf{8}$, 37-40. doi:10.1007/BF02897924

[17] Sauriasari, R., Wang, D.-H., Takemura, Y., Tsutsui, K., Masuoka, N., Sano, K., Horita, M., Wang, B.L. and Ogino, K. (2007) Cytotoxicity of lawsone and cytoprotective activity of antioxidants in catalase mutant. Escherichia Coli. Toxicology, 235, 103-111. doi:10.1016/j.tox.2007.03.019

[18] Miyazaki, M. (1978) Primary culture of adult rat liver cells. II. Cytological and biochemical properties of primary cultured cells. Acta Medica Okayama, 32, 11-22.

[19] Miyazaki, M., Watanabe, A., Shiraishi, M., Hoshika, T., Miyano, K. and Sato, J. (1978) Primary culture of adult rat liver cells. III. Hormonal effects on cytological and biochemical properties of primary cultured cells. Acta Medica Okayama, 32, 85-96. 